\title{
Risk Factors of Hematomyelia Recurrence and Clinical Outcome in Children with Intradural Spinal Cord Arteriovenous Malformations
}

\author{
G. Saliou, A. Tej, M. Theaudin, M. Tardieu, A. Ozanne, M. Sachet, D. Ducreux, and K. Deiva
}

\begin{abstract}
BACKGROUND AND PURPOSE: Few published data are available concerning the risk of re-bleeding of spinal cord AVM after an hematomyelia and concerning the long-term clinical outcome. Our aim was to assess the risk of recurrence and long-term clinical outcome after hematomyelia in children with spinal cord AVMs.
\end{abstract}

MATERIALS AND METHODS: This single-center retrospective study reviewed the clinical and radiologic data of 28 children younger than 18 years of age with arteriovenous malformation who had experienced at least 1 episode of hematomyelia between 1988 and 2012. Long-term clinical outcome was assessed by the American Spinal Injury Association Impairment Scale, and radiologic review included MR imaging and angioarchitecture on angiography (blinded to clinical information) before treatment and at recurrence.

RESULTS: Sixteen children (57\%) experienced 1 episode of hematomyelia, while 12 children (43\%) experienced recurrence. Girls and boys were equally affected (sex ratio, 1:1), and mean clinical follow-up was $5.7 \pm 4.4$ years. The risk of recurrence was higher for AVMs of the cervical and upper thoracic spine, $12(100 \%)$ versus $11(69 \%)(P=.01)$. A high American Spinal Injury Association scale score at last follow-up was reported for 11 children (39\%), and the risk of recurrence tended to be associated with poorer functional prognosis (7 [64\%] versus 5 $[29 \%], P=.07)$. At the time of recurrence, perimedullary venous drainage was the main factor associated with recurrence $(P=.002)$. Occlusion rate $\geq 50 \%$ was associated with a decreased risk of recurrence $(P=.047)$.

CONCLUSIONS: In the present series, cervical and upper thoracic spinal cord AVMs and microarchitecture were predictive of the risk of hematomyelia recurrence. Perimedullary venous drainage was one of the main parameters associated with recurrence. Functional prognosis was better in patients with a single episode of hematomyelia.

ABBREVIATION: ASIA = American Spinal Injury Association

$\mathbf{S}$ pinal cord vascular malformations, particularly arteriovenous malformations, are the most common causes of nontraumatic intraspinal bleeding, called "hematomyelia." 1 Spinal cord AVMs may present with acute neurologic symptoms or deterioration of pre-existing neurologic deficits after hematomyelia. ${ }^{1}$ MR imaging

Received October 1, 2013; accepted after revision December 10.

From the Service de Neuroradiologie (G.S., M.S., D.D., A.O.), Service de Neurologie Pédiatrique (A.T., M. Tardieu, K.D.), and Service de Neurologie (M. Theaudin), Centre Hospitalier Universitaire Bicêtre, National Referral Center for Neurovascular Malformations in Children, Le Kremlin Bicêtre Cedex, France.

Contribution of the authors: Guillaume Saliou: conception and design, acquisition of data and drafting the article, analysis and interpretation of data. Amel Tej: acquisition of data and drafting the article, analysis and interpretation of data. Marie Theaudin: acquisition of data and drafting the article, analysis and interpretation of data. Marc Tardieu: conception and design, drafting the article, analysis and interpretation of data. Augustin Ozanne: acquisition of data and drafting the article, analysis and interpretation of data. Marina Sachet: acquisition of data and drafting the article, analysis and interpretation of data. Denis Ducreux: acquisition of data and drafting the article, analysis and interpretation of data. Kumaran Deiva: acquisition of data and drafting the article, analysis and interpretation of data, statistical analysis.

Paper previously presented in part at: Annual Meeting of the World Federation of Interventional and Therapeutic Neuroradiology, January 15-20, 2012; Cape Town, South Africa. is a useful tool for the diagnosis of hematomyelia and defining the type of vascular injury but may not be sufficient to accurately define the type of injury, the site of the shunt, and the angioarchitecture of the lesion. Angiography is therefore the reference tool for diagnosis, detailed analysis of the angioarchitecture of spinal vascular malformations, and defining the treatment strategy. ${ }^{2}$ Due to the fragility of vascular lesions and their eloquent localization in the spinal cord, partial and targeted treatment can be proposed to avoid deterioration of the neurologic deficit because endovascular treatment is often technically challenging, especially when no specific vascular target is identified. Although a number of angioarchitectural factors associated with an increased risk of bleeding in cerebral AVMs have been described, ${ }^{3-7}$ few published data are available concerning the risk of bleeding of spinal AVMs, particularly predictive factors of intraspinal rebleeding after a first

Please address correspondence to Guillaume Salio, MD-PhD, Service de Neuroradiologie, CHU Bicêtre, 78 rue du General Leclerc, 94275 Le Kremlin Bicêtre Cedex, France; e-mail: guillaume.saliou@bct.aphp.fr

http://dx.doi.org/10.3174/ajnr.A3888 
episode of hematomyelia and predictive factors of long-term clinical outcome. Moreover, endovascular embolization is considered a good option to prevent rebleeding. ${ }^{2,8}$ The primary objective of this study was, therefore, to identify clinical, radiologic, and angiographic factors associated with recurrent hematomyelia in a series of children with hematomyelia. Treatment decisions and targets in the AVM management strategy could be facilitated when only partial removal was acceptable in terms of the risks of treatment, to prevent further bleeding. The secondary objective was to determine the clinical, radiologic, and angiographic factors of clinical severity after a first or subsequent episodes of hematomyelia.

\section{MATERIALS AND METHODS Patient Inclusion}

The patient cohort was extracted from a single-center data base comprising 235 patients with spinal cord AVMs. Among them, 43 patients had a hemorrhage related to a spinal cord AVM. Patients older than 18 years of age ( 5 patients), patients without MR imaging or without clinical or imaging follow-up (3 patients), or patients with isolated subarachnoid hemorrhage secondary to their malformation (7 patients) were excluded from this study. A total of 28 patients younger than 18 years of age with an arteriovenous malformation and at least 1 episode of hematomyelia, followed jointly by the National Referral Center for Neurovascular Diseases in Children and the Pediatric Neurology Department, Hôpitaux Universitaires Paris-Sud, Hôpital Bicêtre, were included in a retrospective study from January 1, 1988, to December 31,2012 . We retrospectively reviewed the following clinical data: date of birth, sex, time of first episode of hematomyelia, date of discovery of the AVM, type of clinical symptoms at onset, date of recurrence, date of last follow-up, and the American Spinal Injury Association (ASIA) Impairment Scale score at onset, at first recurrence, and at last follow-up. We used the following ASIA Impairment Scale: A, complete neurologic deficit with no motor or sensory function; $\mathrm{B}$, incomplete neurologic deficit with sensory but not motor function preserved below the neurologic level; C, incomplete neurologic deficit with motor function preserved below the neurologic level, muscle grade $<3$; D, incomplete neurologic deficit with motor function preserved below the neurologic level, muscle grade $\geq 3$; and E, normal motor and sensory function. ${ }^{9}$ The ASIA scale was assessed retrospectively on the basis of the neurologic reports in the patient charts. A severe ASIA score at onset or at last follow-up was defined by an ASIA Impairment Scale of A, B, or C, while ASIA Impairment Scale D or E was considered not severe.

Most patients were referred to our center for further management of the AVM, and initial management at the acute phase of hematomyelia was therefore performed according to the primary physician's decision. Consequently, surgical decompression of the spinal cord was performed for 6 patients before referral in an effort to improve neurologic recovery. Two patients were treated by laminectomy alone, 2 patients underwent hematoma evacuation, and 2 patients underwent hematoma evacuation and partial nidus excision. One of these last patients experienced worsening of his previous neurologic status, and the other remained stable. First-line management of the malformation was always embolization. Only 1 patient was subsequently referred to another center for surgical excision following failure of AVM catheterization. This patient was lost to clinical follow-up.

When the mass effect resolved after hematomyelia, AVM treatment was always considered as soon as possible to avoid recurrence. All patients were treated by $n$-butyl 2-cyanoacrylate embolization under general anesthesia. The aim of endovascular management was to at least target angioarchitectural weaknesses such as intranidal aneurysms or pseudoaneurysms and to decrease the size of the malformation without inducing glue fragmentation and distal venous embolism. All procedures were performed with the patient under general anesthesia, and no specific monitoring or xylocaine test was used. No anticoagulation was used during endovascular treatment. Embolization was performed in 1 or several sessions in an attempt to cure the disease but was not successful in every case due to safety issues because the benefit/risk balance to cure the patient was sometimes considered unacceptable and only partial embolization was then performed.

\section{Radiologic Assessments}

Imaging review included conventional MR imaging sequences and macro- and microarchitecture on angiography before and after partial or complete treatment. All imaging examinations were reviewed by 2 experienced neurovascular specialists blinded to the diagnosis (G.S. and P. Lasjaunias or M.S.). All except 1 of the patients were assessed by MR imaging at clinical onset of symptoms. For 27 patients, acute hematomyelia was diagnosed in the context of a sudden episode of spinal cord neurologic deficit associated with focal changes on MR imaging: increased diameter of the cord with intraspinal hypointensity on $\mathrm{T} 2{ }^{\star}$ and hyperintensity on T1-weighted sequences surrounded by hyperintense edema on T2-weighted sequences. For 1 patient, hematomyelia was diagnosed on the basis of identical clinical features associated with hyperattenuation in the spinal cord on CT. Spinal cord MR images were analyzed for the size of the ASIA scale lesion on sagittal T2-weighted sequences: T2 hypersignal involving $>3$ vertebrae on sagittal MR imaging and $\mathrm{T} 1$ hyposignal corresponding to a signal identical to that of CSF on T1-weighted sequences.

We studied the following angioarchitectural features: type of arteriovenous malformation (ie, fistula or nidus), number $(1,2$, or 3 versus $>3$ ) and type of arterial feeders (radiculomedullary feeders for arteries that feed the anterior spinal artery in the midline or radiculopial feeders for arteries that feed the ipsilateral posterior spinal cord artery), venous drainage (perimedullary venous drainage, radicular venous drainage, anterior spinal vein drainage, and draining vein stenosis $>50 \%$ ), vascular intranidal dilation (pseudoaneurysm corresponding to the site of vascular rupture, intranidal or draining vein aneurysm or ectasia), treatment (ie, endovascular embolization, surgery, both), and occlusion rate. Because it could not be determined whether the AVM perimedullary venous drainage traveled in a physiologic direction or corresponded to venous reflux, it was called "perimedullary venous drainage" and not "perimedullary venous reflux." All angioarchitectural features were assessed on angiography.

Perimedullary AVM venous drainage was defined as a dilated network around the spinal cord separated from the nidus itself and corresponding to direct drainage of the vascular malformation. A pseudoaneurysm was defined as vascular intranidal dila- 

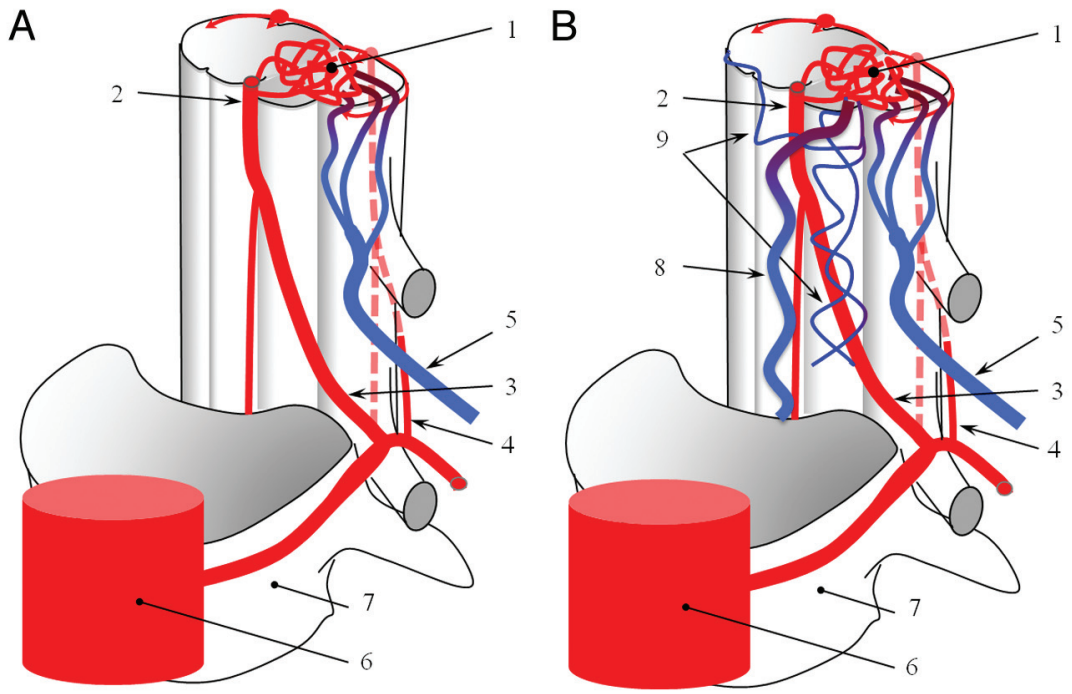

FIG 1. Diagrams of a spinal cord arteriovenous malformation with various venous drainage pathways. A, Nidus AVM drained by a single radicular vein. $B$, Nidus AVM with additional drainage via the anterior spinal vein and perimedullary veins: 1) nidus, 2) anterior spinal artery, 3) radiculomedullary artery, 4) radiculopial artery, 5) radicular vein, 6) aorta, 7) vertebral body, 8) anterior spinal vein, 9) perimedullary venous drainage.


FIG 2. Spinal angiogram without $(A)$ and with $(B)$ digital subtraction and selective injection $(C)$ in a 16-year-old boy with a lower thoracic spinal cord AVM at the time of control after a single episode of hematomyelia (39 months' follow-up). The AVM (open arrow) is fed by a radiculopial artery (single arrow). The AVM is drained by 2 radicular veins (double arrows) and the anterior spinal vein (arrowhead) with no perimedullary venous drainage. tion (either arterial or venous) without a true wall and representing the nonthrombotic portion of the hematoma with a certain degree of contrast pooling on angiography. Anterior spinal vein drainage was assessed on angiography and checked on MR imaging because a single posterior midline longitudinal venous drainage can sometimes be incorrectly interpreted on angiography. Radicular vein drainage was defined as venous drainage through the intervertebral foramina. The various pathways of venous drainage are illustrated in Fig 1, with angiographic findings in Fig 2 and Fig 3. Draining vein stenosis of $\geq 50 \%$ corresponded to a focal decrease in vein diameter by at least one-half. The nidus occlusion rate was assessed by measuring the decrease in the mean radius [ (height + width)/2]. Angiographic cure was defined as the disappearance of the nidus with no persistent arteriovenous shunts. The site of the AVM was classified into 3 groups comprising equal numbers of vertebrae: cervical (C1 to $\mathrm{C} 7)$, upper thoracic ( $\mathrm{T} 1$ to T7), and lower thoracic (T8 to conus medullaris), as previously proposed. ${ }^{10}$

\section{Statistical Analysis}

Statistical analysis was performed with the Statistical Package for the Social Sciences software for Windows (Version 17; IBM, Armonk, New York). Descriptive data were compared by using the $\chi^{2}$ test or Fisher exact test for proportions and a Mann-Whitney test for continuous measurements. Differences were considered significant for $P$ values $<.05$. Three angiographies were analyzed for each patient: the angiography performed at the time of the first or only episode of hematomyelia (Table 1); the angiography performed at the time of recurrence (last episode if several recurrences of hematomyelia) or any angiography performed close to the mean time of angiography performed for children with recurrence and for routine follow-up in children without recurrence (Table 2); and the last angiography performed. Statistical analysis of angiographic findings at the end of follow-up compared the results of the last angiography with the ASIA Impairment Scale (Table 3).

\section{Ethical Issues}

This was a retrospective noninterventional study. No blood tests or clinical investigations 

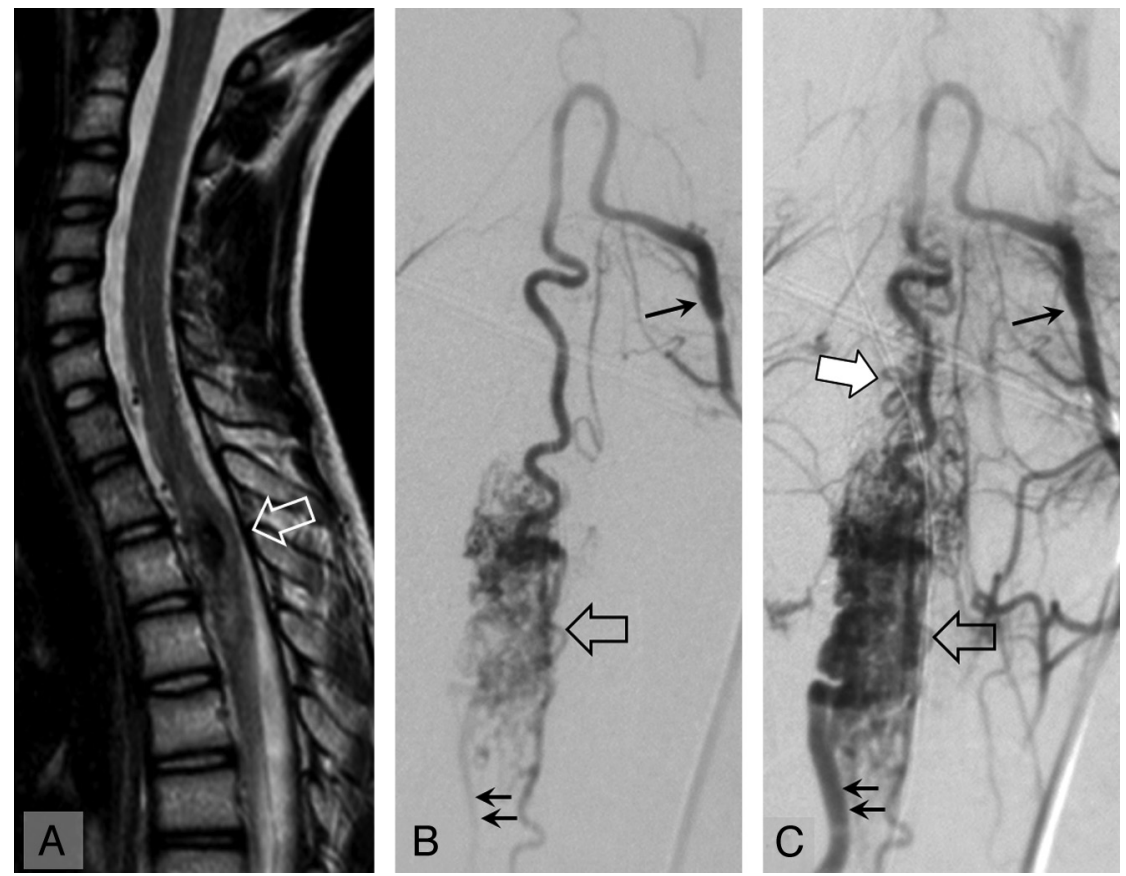

ple AVMs (spinal cord, $n=1$, or cerebral, $n=2)$. Assessment of AVM angioarchitecture showed that fistulas tend to be rare in children with recurrent hematomyelia ( $28 \%$ of fistulas), while a similar percentage of nidus AVMs was observed in the 2 groups. Microarchitectural analysis demonstrated that radiculomedullary arterial feeder $(P=.03)$ and intranidal or draining vein ectasia $(P=.03)$ were observed more frequently in patients with recurrence.

At the time of recurrence (Table 2), perimedullary venous drainage was the main factor associated with recurrence $(P=$ .002 ). An occlusion rate of $\geq 50 \%$ was associated with a decreased risk of recurrence $(P=.047)$, and no recurrence was observed when the occlusion rate was $\geq 70 \%$.

Finally, at the end of treatment, the overall percentage embolization rate was similar for patients with 1 episode of hematomyelia and patients with recurrent episodes (mean/median/ $\pm \mathrm{SD} /$ minimummaximum: $77 \% / 90 \% / \pm 32 / 0 \%-100 \%$ and $72 \% / 85 / \pm 32 / 0 \%-100 \%$, respectively). $(B)$ and late $(C)$ arterial phase in a 15-year-old girl with an upper thoracic spinal cord AVM at the time of recurrence of hematomyelia (29 months' follow-up). On MR imaging, the hematomyelia and AVM are located at T2 (open arrow). On angiography, the AVM (open arrow) is fed by a radiculomedullary artery (single arrow). The AVM is drained inferiorly by a radicular vein (double arrows) and superiorly by perimedullary veins (white arrow).

\section{Functional Prognosis}

Complications related to endovascular were required in addition to standard care of these patients. The study was performed in accordance with French ethical guidelines.

\section{RESULTS}

All 28 malformations were intradural and were classified according to a previous classification ${ }^{11}$ as follows: 18 intramedullary AVMs, 3 juvenile metameric AVMs, 6 intradural dorsal AVFs, and 1 intradural ventral AVF.

\section{Risk of Recurrence of Hematomyelia}

The main initial clinical and radiologic findings are summarized in Table 1. The mean clinical follow-up for the 28 patients was $5.7 \pm 4.4$ years. One or more recurrences were observed in 12 children (43\%), with a mean follow-up of 3.3 years (median, 2.6 years; SD, 2.6 years; minimum, 0.1 year; maximum, 8.9 years) (date of last hematomyelia when $>1$ recurrence). Children with recurrent episodes were older than those without recurrence, but the difference was not statistically significant. At the end of follow-up, 1 patient had experienced 3 episodes of hematomyelia, and 1 patient had experienced 2 episodes of hematomyelia and 1 episode of isolated subarachnoid hemorrhage. Similarly, boys tended to experience more recurrent episodes than girls, but no significant differences were observed in terms of clinical and MR imaging characteristics.

The frequency of spinal cord localization of the AVM was as follows: cervical $(n=16,57 \%)$ followed by upper thoracic $(n=7$; $25 \%)$ and lower thoracic $(n=5 ; 18 \%)$. No recurrences were observed among patients with a lower thoracic AVM $(P=.01)$, while cervical and upper thoracic AVMs were frequently associated with recurrent hematomyelia $(P=.01)$. Twenty-five patients $(89 \%)$ had a single spinal AVM, and 3 patients $(11 \%)$ had multi-

treatment with temporary clinical deterioration were observed in 5 patients. No early hemorrhage (subarachnoid hemorrhage or hematomyelia) related to embolization was observed. Good recovery within 1 month was observed in all of these patients. No permanent deterioration directly related to endovascular embolization was observed.

At last follow-up (Table 3), 11 children (39\%) had a severe ASIA score. Apart from tetraplegia at onset $(P=.03)$, which was significantly more frequent in children with a severe ASIA score at last follow-up, no other clinical or MR imaging characteristics were noted. In angiographic studies, macroarchitecture was unremarkable, but recurrent hematomyelia $(P=.07)$ tended to be associated with a more severe clinical outcome. Endovascular arterial embolization was the treatment of choice for most patients in this population, and endovascular embolization was not performed in only 1 patient (refusal of treatment). A $\geq 90 \%$ decrease of the nidus or angiographic cure was not associated with better clinical outcome, and surgical decompression did not tend to improve clinical outcome.

\section{DISCUSSION}

This study presents the usual limitations of retrospective studies. The main patient recruitment of our institution via our referral center for CNS vascular diseases in children explains the predominant pediatric recruitment and probably explains the different modalities of management compared with series mainly including adults. The mean clinical follow-up was relatively short for the pediatric population, which confers a significant disadvantage in terms of determining the risk of a new episode of bleeding or 


\begin{tabular}{|c|c|c|c|c|}
\hline & $\begin{array}{c}\text { All } \\
\text { Children } \\
\end{array}$ & $\begin{array}{l}\text { Children with } \\
\text { Recurrent } \\
\text { Episodes } \\
\end{array}$ & $\begin{array}{c}\text { Children with } \\
\text { Single } \\
\text { Episode } \\
\end{array}$ & \\
\hline & $(n=28)$ & $(n=12)(43)$ & $(n=16)(57)$ & $P$ \\
\hline Mean age (yr) & $9.9 \pm 5.2$ & $10.1 \pm 5.1$ & $9.7 \pm 5.4$ & NS \\
\hline Male/female & 14:14 & $8: 4$ & $6: 10$ & NS \\
\hline Mean follow-up (yr) & $5.7 \pm 4.4$ & $5.9 \pm 3.2$ & $5.6 \pm 5.3$ & NS \\
\hline \multicolumn{5}{|l|}{ Clinical evaluation } \\
\hline Back pain & $18(64)$ & $7(58)$ & $11(69)$ & NS \\
\hline Tetraplegia & $7(25)$ & $5(42)$ & $2(13)$ & NS \\
\hline Paraplegia & $3(11)$ & $1(33)$ & $2(13)$ & NS \\
\hline Sensory deficit & $19(68)$ & $10(83)$ & $9(56)$ & NS \\
\hline Respiratory distress & $4(15)$ & $3(25)$ & $1(7)$ & NS \\
\hline Sphincter dysfunction & $18(64)$ & $9(75)$ & $9(56)$ & NS \\
\hline Severe ASIA score at onset $(<D)$ & $20(71)$ & $7(58)$ & $13(81)$ & NS \\
\hline Severe ASIA score at last follow-up & $11(39)$ & $7(58)$ & $4(25)$ & NS \\
\hline \multicolumn{5}{|l|}{ MRI characteristics at onset $(n=22)$} \\
\hline Size of lesions $>3$ vertebrae $(n=20)$ & $14(70)$ & $4(57)$ & $10(77)$ & NS \\
\hline T1 hyposignal $(n=15)$ & $6(40)$ & $3(43)$ & $3(38)$ & NS \\
\hline \multicolumn{5}{|l|}{ Angiographic evaluation at onset } \\
\hline \multicolumn{5}{|l|}{ Macroarchitecture } \\
\hline Fistula & $7(25)$ & $2(17)$ & $5(31)$ & NS \\
\hline Nidus & $21(75)$ & $10(83)$ & $11(69)$ & NS \\
\hline \multicolumn{5}{|l|}{ Site } \\
\hline Cervical & $16(57)$ & $8(67)$ & $8(50)$ & NS \\
\hline Upper thoracic (T1-T7) & $7(25)$ & $4(33)$ & $3(19)$ & NS \\
\hline Lower thoracic (T8-conus) & $5(18)$ & 0 & $5(31)$ & .01 \\
\hline Cervical and upper thoracic & $23(82)$ & $12(100)$ & $11(69)$ & .01 \\
\hline \multicolumn{5}{|l|}{ Microarchitecture } \\
\hline Perimedullary venous drainage & $27(96)$ & $12(100)$ & $15(94)$ & NS \\
\hline Radiculomedullary arterial feeder & 20 (71) & $11(92)$ & $9(56)$ & .03 \\
\hline Anterior spinal vein drainage & $9(33)$ & $5(42)$ & $4(27)$ & NS \\
\hline No. of arterial feeders $>3(n=26)$ & $15(58)$ & $8(73)$ & $7(47)$ & NS \\
\hline Draining vein stenosis $\geq 50 \%(n=26)$ & $3(12)$ & $1 / 11(9)$ & $2 / 15(13)$ & NS \\
\hline Pseudoaneurysm $(n=23)$ & $9(39)$ & $4 / 9(44)$ & $5 / 14(36)$ & 1 \\
\hline $\begin{array}{l}\text { Intranidal or draining vein ectasia } \\
(n=24)\end{array}$ & $14(58)$ & $9 / 10(90)$ & $5 / 14(36)$ & 0.03 \\
\hline Radicular vein drainage & $23(82)$ & $9(75)$ & $14(88)$ & NS \\
\hline \multicolumn{5}{|l|}{ Treatment } \\
\hline Angiographic cure $(n=27)$ & $5(19)$ & $0 / 12$ & $5 / 15(33)$ & 0.01 \\
\hline Surgical decompression & $6(21)$ & $2(17)$ & $4(25)$ & 0.6 \\
\hline
\end{tabular}

Higher pressure inside the AVM would therefore be associated with a higher risk of bleeding.

A high occlusion rate was correlated with a lower risk of recurrence. An occlusion rate $\geq 50 \%$ was associated with a lower recurrence rate $(P=.047)$. We can hypothesize that a nidus whose size was decreased by treatment was associated with lower blood pressure inside it and a lower risk of recurrent hematomyelia. When venous drainage is preserved during treatment, a decrease in the size of the nidus would proportionally decrease the pressure. In a 2007 study, Corkill et al ${ }^{15}$ obtained a high occlusion rate with injection of Onyx (Covidien, Irvine, California). Although the occlusion rate was not specified, embolization achieved total or subtotal obliteration in $69 \%$ of cases with this liquid embolic system. A significant reduction of the flow load was obtained in the remaining patients, though a substantial part of the nidus remained patent. In their series, no recurrence of hematomyelia was reported with a mean follow-up of 24.3 months. The shorter follow-up in that study probably cannot explain this discrepancy in terms of recurrence rate compared with our series because the mean time to recurrence in our series was $3.7 \pm 2.7$ years. The absence of recurrence of hematomyelia could also be explained by the high mean obliteration rate achieved by Onyx injection. However, it seems difficult to transpose this technique to our population, which was mainly chil-

disability. In the present study, no significant difference in mean age was observed between patients with recurrence and patients without recurrence. Although the risk of bleeding at presentation has been previously described to be lower in adults than in children ${ }^{1,8,12-14}$ due to the peak incidence at the growth spurt, the risk of recurrence does not appear to be different in a pediatric population.

The main result of this study is that the risk of recurrence of hematomyelia was increased in a particular condition: malformative perimedullary venous drainage $(P=.002)$. All patients who had a recurrence had perimedullary venous drainage compared with $33 \%$ of patients with a single episode of hematomyelia. This increased risk can be explained by a hypothesis based on mechanical considerations. Perimedullary venous drainage involves relatively small veins, while radicular venous drainage involves larger veins. However, venous drainage involving small veins may reflect higher upstream blood pressure inside the nidus. Because the outlet is smaller, it could interfere with venous outflow and could be responsible for higher blood pressure inside the AVM. dren, while the study by Corkill et al mainly concerned adults.

A high rebleeding rate (43\%) was observed in this study. Although few data are available in the literature concerning the real frequency of hematomyelia and recurrence, the risk of recurrence was higher than that reported after similar treatment (a similar acrylic agent such as $n$-butyl 2-cyanoacrylate or Glubran Tiss [Aspide Medical, La Talaudière, France]; 18\%, 2/11 patients) ${ }^{1}$ in an exclusively pediatric population, while no recurrences were observed after the use of Onyx. ${ }^{15}$ Several explanations can be proposed for the high recurrence rate observed in our series: In 50\% of cases ( 6 patients), rebleeding occurred before the first treatment session (failure of embolization $[n=1]$ ) or while the patient was waiting for transfer to our institution for embolization ( $n=$ $5)$; these scenarios could explain why recurrence occurred and why the risk of rebleeding of spinal cord AVMs appears to be higher in the absence of treatment. Partial treatment was initiated for the remaining 6 patients who rebled: Three were treated surgically with partial removal of the hematoma and resection of the malfor- 
Table 2: Angiographic characteristics at recurrence or in children with a single episode of hematomyelia on angiography performed close to the mean time of the angiography performed in children with recurrence

\begin{tabular}{|c|c|c|c|}
\hline \multirow[b]{2}{*}{ Microachitecture } & $\begin{array}{l}\text { Children with } \\
\text { Recurrent } \\
\text { Episodes } \\
\end{array}$ & 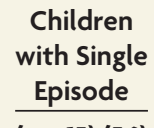 & \multirow[t]{2}{*}{$P$} \\
\hline & $(n=12)(44)$ & $(n=15)(56)$ & \\
\hline \multicolumn{4}{|l|}{ Follow-up (yr) } \\
\hline Median & $2.8(0.10-9.3)$ & $1.3(0.4-4.8)$ & NS \\
\hline Mean & $3.7 \pm 2.7$ & $1.8 \pm 1.3$ & NS \\
\hline Cure & 0 & $5(33)$ & \\
\hline Radiculomedullary feeder alone & $3(25)$ & $1(7)$ & NS \\
\hline Radiculopial feeders alone & $8(67)$ & $5(33)$ & NS \\
\hline Combination of both feeders & $1(8)$ & $5(33)$ & NS \\
\hline Anterior spinal vein drainage & $4(33)$ & 0 & NS \\
\hline Radicular vein drainage & $7(58)$ & $8^{a}(53)$ & NS \\
\hline $\begin{array}{l}\text { Anterior spinal and radicular } \\
\text { vein drainage }\end{array}$ & $1(8)$ & $2^{a}(13)$ & NS \\
\hline Perimedullary vein drainage & $12(100)$ & $5(33)$ & .002 \\
\hline Intranidal ectasia & $6(50)$ & $2(15)$ & .01 \\
\hline $\begin{array}{l}\text { Draining vein stenosis } \geq 50 \% \\
\qquad(n=26)\end{array}$ & $1 / 11(9)$ & $2(13)$ & NS \\
\hline Pseudoaneurysm ( $n=23$ ) & $2(17)$ & 0 & NS \\
\hline Occlusion rate $\geq 50 \%$ & $4(33)$ & $10(66)$ & .047 \\
\hline Occlusion rate $\geq 70 \%$ & 0 & $10(66)$ & \\
\hline
\end{tabular}

Note:-NS indicates not significant.

${ }^{a}$ For children with a single episode, radicular vein, or a combination of radicular and anterior spinal veins, drainage was associated with perimedullary vein drainage in $50 \%$ of cases.

mation and 3 were treated by partial embolization. Only a small percentage of malformations were removed (mean percentage of treatment, 38\%); this finding could also help to explain recurrence.

Cervical AVM has been reported as associated with a higher risk of hematomyelia. ${ }^{1}$ This appeared to be the case in our series because $57 \%$ of AVMs were cervical (16 patients), which was much more frequent, though not significantly, than upper thoracic (25\%; 7 patients) and lower thoracic sites (18\%; 5 patients). Although the risk of recurrence was not significantly higher for cervical AVMs, a lower risk of recurrence was observed in the lower thoracic spine $(P=.01)$, in which no recurrences were observed. In lesions situated more caudally in the spinal canal, the Adamkiewicz artery may be frequently involved in the malformation. These AVM sites were considered very eloquent lesions, as in 3 of the 5 cases in this study. This lower recurrence rate can be explained by the high mean occlusion rate (95\%) in this group of lower thoracic AVMs. The high mean occlusion rate can probably be explained by angioarchitectural findings because fistulas were more frequently observed in this site $(63 \%, 3 / 5$ patients) than in cervical (19\%, $3 / 16$ patients) or upper thoracic sites $(28 \%, 2 / 7$ patients). This angioarchitecture is usually easier to treat due to the presence of a smaller number of feeders usually presenting a good caliber that are easier to catheterize than in nidus AVMs with multiple small feeders.

Intranidal aneurysms have been more frequently described in the spinal cord with bleeding on presentation, ${ }^{1}$ as in our cases of recurrence $(P=.01)$. When possible, intranidal aneurysms should therefore be a target of choice during embolization, especially when only a small part of the malformation is removed.

The present study was based on patients with one or several
Table 3: Clinical and angiographic characteristics according to the ASIA scale at last follow-up ${ }^{a}$

\begin{tabular}{|c|c|c|c|}
\hline & $\begin{array}{c}\text { Severe } \\
\text { ASIA } \\
\text { Scale } \\
\end{array}$ & $\begin{array}{c}\text { Nonsevere } \\
\text { ASIA } \\
\text { Scale } \\
\end{array}$ & \\
\hline Characteristics & $(n=11)(39)$ & $(n=17)(61)$ & $P$ \\
\hline Mean age at onset (yr) & $9.2 \pm 6.4$ & $10.4 \pm 4.3$ & NS \\
\hline Male/female & $6: 5$ & $8: 9$ & NS \\
\hline Mean follow-up (yr) & $6.0 \pm 4.5$ & $5.5 \pm 4.5$ & NS \\
\hline \multicolumn{4}{|l|}{ Clinical evaluation } \\
\hline Back pain & $6(55)$ & $12(71)$ & NS \\
\hline Tetraplegia & $6(55)$ & $1(6)^{\prime}$ & .03 \\
\hline Paraplegia & $1(9)$ & $2(12)$ & NS \\
\hline Sensory deficit & $9(82)$ & $10(59)$ & NS \\
\hline Respiratory distress & $2(20)$ & $2(12)$ & NS \\
\hline Sphincter dysfunction & $9(82)$ & $9(53)$ & NS \\
\hline Severe ASIA score at onset (<D) & $9(82)$ & $11(65)$ & NS \\
\hline Recurrence of hematomyelia & $7(64)$ & $5(29)$ & .07 \\
\hline \multicolumn{4}{|l|}{ MRI characteristics at onset $(n=22)$} \\
\hline $\begin{array}{l}\text { T2 hyperintensity }<3 \text { vertebrae } \\
\quad(n=20)\end{array}$ & $6(75)$ & $8(67)$ & NS \\
\hline T1 hypointensity $(n=15)$ & $4(67)$ & $2(22)$ & NS \\
\hline \multicolumn{4}{|l|}{ Angiographic evaluation } \\
\hline \multicolumn{4}{|l|}{ Macroarchitecture } \\
\hline Fistula & $2(18)$ & $5(29)$ & NS \\
\hline Nidus & $9(82)$ & $12(71)$ & NS \\
\hline \multicolumn{4}{|l|}{ Site } \\
\hline Cervical & $7(64)$ & $9(53)$ & NS \\
\hline Upper thoracic (T7-T7) & $2(18)$ & $5(29)$ & NS \\
\hline Lower thoracic (T8-conus) & $2(18)$ & $3(18)$ & NS \\
\hline Cervical and upper thoracic & $9(82)$ & $14(82)$ & NS \\
\hline Surgical decompression at onset & $2(18)$ & $4(24)$ & NS \\
\hline Angiographic cure ( $\geq 90 \%)$ & $7(64)$ & $8(50)$ & NS \\
\hline
\end{tabular}

Note:-NS indicates not significant.

a Percentages are shown in parentheses.

episodes of hematomyelia, and the results cannot be extrapolated to patients with spinal cord AVMs that never bleed. However, because of the rarity of these malformations, it would be difficult to conduct a prospective study in patients with nonbleeding spinal cord AVMs to assess the angiographic criteria associated with an increased risk of bleeding. When endovascular treatment is required, at least a $50 \%$ reduction of the AVM and especially obliteration of the perimedullary venous drainage could be considered as a treatment option when cure of the lesion is not associated with an acceptable benefit/risk balance. Moreover, a $>90 \%$ decrease or anatomic cure was not associated with a better clinical outcome. Although this study was based on a small population, it supports the hypothesis that cure of malformations situated in high eloquent areas is not required to improve clinical outcome and prevent recurrence of hematomyelia.

Finally, regarding the late clinical outcome, it is not surprising that recurrences were associated, though not significantly, with poorer outcome, because $64 \%$ of patients with recurrence had a severe ASIA score (ie, A, B, or C), while a severe outcome was observed in only $29 \%$ of patients without recurrence. These results suggest that treatment should be performed to prevent recurrence, which certainly constitutes one of the main parameters responsible for poorer outcome.

In this study, no clinical symptoms were associated with an increased risk of recurrence or severe ASIA score. In other my- 
elopathies, particularly inflammatory myelopathies in children, younger age at onset and the presence of sphincter involvement were associated with a poorer clinical prognosis. ${ }^{16,17}$ Imaging studies revealed that $\mathrm{T} 1$ hyposignal and extensive lesions could be MR imaging signs predictive of poorer outcome. In our study, we did not observe any clinical or MR imaging criteria able to distinguish recurrence or more severe ASIA scale apart from younger age, though not significant, suggesting that these factors are less important in hematomyelia in contrast to inflammatory myelopathies.

\section{CONCLUSIONS}

The treatment of spinal cord AVM while avoiding neurologic sequelae is challenging. In the presence of hematomyelia, treatment must prevent recurrence that can worsen the clinical status. When cure of the malformation is not associated with an acceptable benefit/risk balance, a 50\% decrease of the malformation can constitute a good option to prevent further recurrence. Disappearance of perimedullary venous drainage appears to be 1 primary target of treatment to avoid recurrences.

\section{ACKNOWLEDGMENTS}

We thank Professor Pierre Lasjaunias for his contribution in the collection of the clinical and imaging data as well as his overall contribution to our understanding of spinal cord AVMs.

Disclosures: Marie Theaudin—UNRELATED: Travel/Accommodations/Meeting Expenses Unrelated to Activities Listed: Biogen Idec, Novartis, Merck Serono, Bayer, LFB Biomedicaments. Marina Sachet-UNRELATED: Travel/Accommodations/ Meeting Expenses Unrelated to Activities Listed: Covidien, Other: Covidien, * Balt,* MicroVention, ${ }^{\star}$ Comments: fees for participation in review activities such as datamonitoring boards, statistical analysis, endpoint committees, and the like. Kumaran Deiva-UNRELATED: Travel/Accommodations/Meeting Expenses Unrelated to Activities Listed: Merck Serono, Biogen Idec, Comments: travel grants for meetings, but no money received directly (accommodations booked directly by companies), Principal Investigator for Merck Serono. *Money paid to the institution.

\section{REFERENCES}

1. Rodesch G, Hurth M, Alvarez H, et al. Angio-architecture of spinal cord arteriovenous shunts at presentation: clinical correlations in adults and children - the Bicêtre experience on 155 consecutive patients seen between 1981-1999. Acta Neurochir (Wien) 2004;146: 217-26, discussion 226-27

2. Rodesch G, Lasjaunias P. Spinal cord arteriovenous shunts: from imaging to management. Eur J Radiol 2003;46:221-32
3. Hernesniemi JA, Dashti R, Juvela S, et al. Natural history of brain arteriovenous malformations: a long-term follow-up study of risk of hemorrhage in 238 patients. Neurosurgery 2008;63:823-29, discussion 829-31

4. Halim AX, Johnston SC, Singh V, et al. Longitudinal risk of intracranial hemorrhage in patients with arteriovenous malformation of the brain within a defined population. Stroke 2004;35:1697-702

5. Mast H, Young WL, Koennecke HC, et al. Risk of spontaneous haemorrhage after diagnosis of cerebral arteriovenous malformation. Lancet 1997;350:1065-68

6. Stapf C, Mast H, Sciacca RR, et al. Predictors of hemorrhage in patients with untreated brain arteriovenous malformation. Neurology 2006;66:1350-55

7. Stefani MA, Porter PJ, terBrugge KG, et al. Angioarchitectural factors present in brain arteriovenous malformations associated with hemorrhagic presentation. Stroke 2002;33:920-24

8. Rodesch G, Pongpech S, Alvarez H, et al. Spinal cord arteriovenous malformations in a pediatric population children below 15 years of age: the place of endovascular management. Interv Neuroradiol 1995; 1:29-42

9. Maynard FM Jr, Bracken MB, Creasey G, et al. International Standards for Neurological and Functional Classification of Spinal Cord Injury: American Spinal Injury Association. Spinal Cord 1997;35:266-74

10. Du J, Ling F, Chen M, et al. Clinical characteristic of spinal vascular malformation in pediatric patients. Childs Nerv Syst 2009;25:473-78

11. Kim LJ, Spetzler RF. Classification and surgical management of spinal arteriovenous lesions: arteriovenous fistulae and arteriovenous malformations. Neurosurgery 2006;59(5 suppl 3):S195-201, discussion S3-13

12. Emery DJ, Willinsky RA, Burrows PE, et al. Paediatric spinal arteriovenous malformations: angioarchitecture and endovascular treatment. Interv Neuroradiol 1998;4:127-39

13. Scarff TB, Reigel DH. Arteriovenous malformations of the spinal cord in children. Childs Brain 1979;5:341-51

14. Cullen S, Alvarez H, Rodesch G, et al. Spinal arteriovenous shunts presenting before 2 years of age: analysis of 13 cases. Childs Nerv Syst 2006;22:1103-10

15. Corkill RA, Mitsos AP, Molyneux AJ. Embolization of spinal intramedullary arteriovenous malformations using the liquid embolic agent, Onyx: a single-center experience in a series of 17 patients. J Neurosurg Spine 2007;7:478-85

16. Pidcock FS, Krishnan C, Crawford TO, et al. Acute transverse myelitis in childhood: center-based analysis of 47 cases. Neurology 2007;68:1474-80

17. Thomas T, Branson HM, Verhey LH, et al. The demographic, clinical, and magnetic resonance imaging (MRI) features of transverse myelitis in children. J Child Neurol 2012;27:11-21 